\title{
Brief Field Experiences: An Instructional Tool For Undergraduate Political Science Classes
}

\author{
Rosalie R. Young, State University of New York at Oswego
}

\begin{abstract}
Adding a brief field project to political science classes injects excitement and stimulates an interest in course material (Kendall et al. 1986, 11), while exposing students to some of the agencies, professionals, clients, and issues discussed in the classroom. After a field experience, students who otherwise rarely participate in discussion are frequently willing to share their observations and insights.
\end{abstract}

\section{Assignment Options}

For introductory American government courses, I require students to attend a public forum, community meeting, or legislative session. In reaction papers, students are urged to consider any pre-meeting publicity, public accessibility of the meeting sites and times, and participant interaction, as well as the opportunity for community members to air their opinions. After the event, class members must appraise the quality, quantity, and emphasis of the media coverage. Students often question whether they and the reporters had attended the same meeting and these students thus learn to evaluate news reports more carefully.

Students become involved in searching the media or calling government agencies for information on hearings or legislative sessions. Most agency personnel have been generous in sharing their ideas, steering students toward meetings involving stimulating debate or potential political fireworks. Students are surprised by the unexpected graciousness of some contacts and the unforeseen rudeness of others. Both ease of access and apparent hostility provide a learning experience as students consider how difficult it might be for the "average citizen" to learn about important community meetings.

For more advanced classes, students make two visits to a community agency whose focus relates to their current course. Two observa- tions are required because students are generally so self-conscious on their first exposure that their ability to observe those around them is restricted. Participants are encouraged to explore possible field sites on their own, with minimal instructor guidance. During their search for an agency, students evaluate the obstacles confronting prospective agency clients who might be hindered by limited personal resources or by the stress of their crises.

In their papers, students must summarize their reactions to each of their visits, noting the physical setting, atmosphere, staff, clients, and the location and hours of operation. Finally, students are urged to reflect on the differences between their initial expectations and their actual observations. Students may enter the field in pairs, although each must prepare their own paper.

Class members have chosen various sites, including family, criminal, or village courts, homeless shelters, public assistance application divisions, police departments, and hospital emergency rooms. Depending upon the community and course, numerous other options arise, including legislative sessions, political party meetings, police academies, geriatric facilities, or soup kitchens. Some students are able to meet with agency officials, including presiding judges, legislators, shelter directors, and court clerks. Officials appear to enjoy the opportunity to educate the next generation of professionals, and students learn much from personal contact with professionals.

\section{Student Reactions}

Students may have quite disparate responses to the same agency or forum as a result of personal issues, interactions with staff, or their own communication skills. Recently, for instance, two students observed the waiting room of a public assistance applications division. One was so uncomfortable that she had trouble completing the assignment, ultimately finding that she had learned as much about her biases as she had about the setting. The other student at the public assistance office chatted with frustrated applicants during their long wait to be interviewed. She discovered that the needs and prejudices of potential recipients reflected those of the general community. After a lengthy visit to the office, this student learned that she and many applicants were bound to a bus schedule that was more conveniently arranged for agency employees than for public assistance clients.

Another student visited a New York City homeless shelter. For many years, he had avoided the agency and its occupants by walking to the other side of the street whenever he passed the building. After a tour of the facility and conversations with shelter residents, this student's views of the homeless population were greatly altered.

While watching long lines of defendants awaiting arraignment or trial, students gain a better understanding of the pressures on judges, attorneys, and support staff. Students frequently witness the same clients returning to the courtroom on new charges, and they see the frustration of justice system personnel who meet "repeat offenders" with regularity.

Students are often fascinated by lengthy hearings on topics they had previously ignored. After observing a five hour community debate on the benefits and dangers of aerial spraying for disease-carrying mosquitos, one student noted with exasperation: "Both sides made sense."

\section{Time Involvement}

Students average four hours in the field. Because of the option to visit 24 hour facilities or courts with week-end and evening hours, none of the students find this assignment unreasonable. Vacations within the 
semester permit some students to expand their observational options to other communities.

Students visiting agencies during off-hours may see the repercussions of staff shortages or encounter the unexpected. One pair of students visiting a city court on a week-end viewed both arraignments and weddings. Another student, with limited time and transport wrote his paper about college financial aid applicants and the staff who responded to their needs.

\section{Dangers and Opportunities}

I have used brief field assignments for both lower and upper division courses, in day and evening classes, and in cities of various sizes. In every instance, I find that students learn from their own activities and from the observations of their classmates.
There is a danger that students may make erroneous generalizations from their brief field experiences. To rectify this problem, class members can be required to give short oral reports, comparing their impressions with peers who had similar experiences. Even a brief exchange contributes to class members' understanding of governmental processes.

Participants often refer to these field projects long after the end of the course. They describe their firsthand exposure as a highlight that enhanced their involvement with and understanding of class material.

\section{Reference}

Kendall, Jane C., John S. Duley, Thomas C. Little, Jane S. Permaul and Sharon Rubin. 1986. "Why Experiential Learning." In Strengthening Experiential Education within
Your Institution. Raleigh, North Carolina: National Society for Internships and Experiential Education. Reprinted from "A Nation at Risk: Another View," Experiential Education Newsletter, NSIEE, MarchApril, 1984.

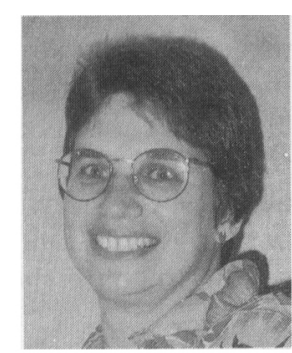
subsidized legal services.

\title{
Deconstructing the Other: Teaching the Politics of the Middle East
}

\author{
Mary Ann Tétreault, Iowa State University
}

Teaching comparative politics is an occupation with many built-in difficulties. First, there are problems not simply in choosing which cases to compare, but also in choosing the dimensions along which these cases will be compared. Second, the amount of information necessary to make interesting comparisons can be overwhelming, especially in an intercontinental region of more than twenty countries. For those teaching Middle Eastern politics, there is an additional difficulty: the perception among many American students that the Middle East and its people are irredeemably "Other," different in fundamental ways from every other population and culture in the world.

This sense of Middle Easterners as Other goes beyond perceiving them as exotic, and even beyond viewing them through the scrim of orientalism as described by analysts such as Edward Said (1979). It is equally the product of years of U.S. domestic politics and media coverage that have transformed what were once descriptive nouns and adjectives into reflexive, pejorative tropes: "Palestinian terrorist," "Iranian revolutionary," "Islamic militant," and many more. Etched in our brains by video footage showing military equipment, women in chadors, rioting crowds, and leaders in costumes, these pejoratives are chanted in presumably objective voiceovers emanating from putatively rational news analysts. Media reports not only mystify, they demonize, making it essential for the teacher of Middle East Politics to restore humanity to the population and combat the bias that often underlies Americans' understanding of Middle Easterners and their politics.

This discussion of strategies to overcome some of these difficulties is divided into three sections: boundaries, bases of information, and boredom. Throughout, I address the difficulties of teaching Middle Eastern politics and the problem of deconstructing the Other. In general, my approach is to emphasize similarities and commonality of interest, both among actors within the Middle East and between Middle Eastern leaders, businessmen, and citizens, and Americans in these same roles.

\section{Boundaries}

The question of boundaries is one that can be usefully incorporated directly into class material: what is the Middle East-and what is it in the middle of? Answers lead directly to a consideration of colonialism and the geopolitical construction of the Middle East according to the perspectives and objectives of western imperialists and statesmen-two categories with considerable overlap. ${ }^{1}$ These issues, in turn, spark discussions of ethnicity, religion, language, common histories, and they suggest 